\title{
OFF-LABEL AND UNLICENSED PRESCRIBING IN PEDIATRIC INPATIENTS WITH NEPHROTIC SYNDROME IN A MAJOR TEACHING HOSPITAL: AN INDONESIAN CONTEXT
}

\author{
HESTY U RAMADANIATI ${ }^{1 *}$, TARALAN TAMBUNAN ${ }^{2}$, SONDANG KHAIRANI ${ }^{1}$, HAPPY S ADISTY ${ }^{1}$
}

${ }^{1}$ Department of Clinical and Community Pharmacy, Faculty of Pharmacy, Pancasila University, Jakarta, Indonesia. ${ }^{2}$ Department of Pediatrics, Cipto Mangunkusumo Hospital, Jakarta, Indonesia. Email: h.ramadaniati@postgrad.curtin.edu.au

Received: 30 September 2016, Revised and Accepted: 12 October 2016

\section{ABSTRACT}

Objective: To estimate the prevalence of off-label and unlicensed prescribing in pediatric inpatients with nephrotic syndrome in a major teaching hospital in Indonesia.

Methods: A retrospective study was conducted in study hospital using medical records from pediatric inpatients with nephrotic syndrome during the period of January-December 2015. Patient and prescribing data were collected, and drugs were classified as on-label or off-label/unlicensed based on the Indonesia National Drug Information (IONI). Thereafter, off-label drugs were categorized with a hierarchical system of age, indication, route of administration, and dosage.

Results: There were 1553 drugs with 94 different types of drug administered to 67 patients during the study period. The data uncovered that $1023(65.9 \%)$ of the drug prescriptions were used either off-label/unlicensed. Most off-label drugs ( $\mathrm{n}=433,42.4 \%)$ were from nondiuretics antihypertensive drugs. The most common drugs used in an off-label/unlicensed manner were prednisolone and lisinopril. The high rate of off-label drug use in children was mainly related to age $(n=772,75.5 \%)$. Pediatrics with nephrotic syndrome was vulnerable to off-label uses where every patient received at least two off-label drugs. It seems that off-label prescribing in pediatric with nephrotic syndrome was not influenced by age or gender as every patient received off-label drugs.

Conclusion: Despite the high prevalence of off-label use in pediatric patients with nephrotic syndrome, this use is supported by evidence-based prescribing. Further, there remains a need for supporting clinical trials for pediatric drugs and updating IONI as the standard drug information in Indonesia to provide complete product information for pediatric use.

Keywords: Off-label drug, Syndrome nephrotic, Inpatient, Pediatrics.

(c) 2017 The Authors. Published by Innovare Academic Sciences Pvt Ltd. This is an open access article under the CC BY license (http://creativecommons. org/licenses/by/4. 0/) DOI: http://dx.doi.org/10.22159/ajpcr.2017.v10i1.15477

\section{INTRODUCTION}

It has been stated clearly that each medicine should be used in the rational manner, in which the medicines should be safe, effective, and affordable. One of the measures to support the rational use of medicine is ensuring the medicines are prescribed in correspond with their product labels. Drug label is the official information of a drug product provided by a pharmaceutical company during the registration process and approved by an authorized institution (i.e., Food and Drug Administration in the United States, National Agency of Food and Drug Control in Indonesia). In addition to evidence-based medicine, the drug label can be used by health-care professional as the guidance during their practice to benefit patients [1].

The term "off-labels" refers to use of a drug that is not included in the product labeling for that drug (unapproved indication, unapproved age range, unapproved dosage, or unapproved route of administration) [1]. Meanwhile, unlicensed prescribing is defined as the use of unregistered drugs or nonpharmacological substance as a medicine, modification/ reformulation of a licensed drug to obtain the desired dose or to ease its administration and formulation manufactured under a special license [2]. It is of importance to note that the absence of labeling in pediatric patients does not necessarily imply that the use of the medicine is inappropriate and unsupported by evidence. Rather, it possibly points out that evidence for drug safety and efficacy in the pediatric population has not been submitted for review or has not met the regulatory standards of "substantial evidence" for approval by the authorized institution [1]. As a result, off-label and unlicensed use of drugs has become a worldwide phenomenon, particularly in pediatric patients.

There are some main reasons for the scarcity of substantial evidence for supporting drug labeling in pediatrics. Clinical trials in children are limited due to ethical consideration and practical difficulties, especially when dealing with young children. Reluctance of parents to give permission for their children as the trial participants has added another barrier for this matter. In addition, children merely account for the minority of the population in the drug market. From the economy perspective, it is not profitable for pharmaceutical industry to undertake extensive clinical trials in this population [3]. Consequently, a considerable number of medicines prescribed for children have not been studied specifically in the pediatric population and lack of pediatric information occurs. In addition, it is not uncommon that the dosages for children are extrapolated from data of clinical trials conducted in their counterpart population [4]. This situation may lead to children being referred to as "therapeutic orphans" [5].

It has been evident that off-label studies have been carried out in a range of pediatric settings, and intriguingly, the evident reveals a similar fact highlighting the high rate of off-label use in children [2,3,6-8]. However, it is interesting to note that limited studies have been done on the off-label drug use in the area of pediatric nephrology. Further, the information about the use of off-label drugs in pediatric, especially pediatric with nephrotic syndrome is still lacking. Nephrotic syndrome is responsible for one of the major chronic diseases in children, and subsequently, the patients should take their medicines for the long- 
term period [9]. Thus, this study aimed to estimate the prevalence of off-label and unlicensed prescribing in pediatric inpatients with nephrotic syndrome in a national referral hospital in Indonesia.

\section{METHODS}

A retrospective study was conducted in a 72-bed pediatric ward in a major teaching hospital in Indonesia during the period of January-December 2015. There were approximately 24,000 hospital admissions to the ward during the study period. The data were collected from medical records of pediatric patients with nephrotic syndrome hospitalized to pediatric ward during the study period. Patients with incomplete data were excluded. The data collected included patient characteristics (date of birth, sex, weight, height, past medical history, diagnosis, length of stay, and number of medications prescribed during hospitalization) and prescribing details (date of prescription data, dose, dosage form, strength of drug, and dosing frequency/interval). The patient's age was classified according to the European Medicines Agency age classification: Newborns (0-27 days), infants and toddlers (28 days-23 months), children (2-11 years), and adolescents (12-18 years) [10].

Drugs were classified as on-label or off-label/unlicensed based on the Indonesia National Drug Information (IONI) 2015 [11]. Off-label drugs were categorized with a hierarchical system established by Hsien et al. [12] Categories of off-label were defined as follows:

- Age/weight: Administration of a prescribed drug outside the age range or weight for which the product is licensed.

- Indication: Prescribed for indication not mentioned in the product label.

- Route of administration: The use of alternative routes of administration other than the approved route for that formulation in the product label.

- Dosage (including dose and frequency): The use of doses or dose frequencies not stated in the approved product label.

Table 1: Patients' demographic characteristics and data related to disease

\begin{tabular}{ll}
\hline During the study period (N=67) & \\
\hline Patient characteristics & Value \\
\hline Age group (\%) & 0 \\
$\quad$ Newborns (0-27 days & $2(2.9)$ \\
Infants and toddlers (28 days 23 months) & $32(47.8)$ \\
Children (2-11 years) & $33(49.3)$ \\
Adolescents (12-18 years) & \\
Gender (\%) & $45(67.2)$ \\
Male & $22(32.8)$ \\
Female & $4(1-46)$ \\
Median length of stay in days (range) & $1(1-12)$ \\
Median number of hospital admission (range) & \\
Number of disease complications (\%) & $26(38.8)$ \\
None & $26(38.8)$ \\
1 Complication & $15(22.4)$ \\
2 Complications &
\end{tabular}

A drug was considered off-label if met at least one of the above criteria according to IONI 2015. A sequential approach was used for this study, in which all prescription drugs were initially analyzed for age. Drugs with no pediatric information or those prescribed for an age group for which the drug was not licensed were classified as off-label for age. The next level was indication, route of administration, and dosage subsequently. Once drugs were classified into a higher level (e.g. off-label category for age), those drugs were not analyzed for possible classification into any subsequent category [12]. Further, drugs were categorized unlicensed if they were unregistered drugs, unlicensed formulations of registered drugs or the use of nonpharmacological substances as medicines [2]. In case where a drug was classified both off-label and unlicensed, the final classification was off-label. The drugs were classified based on the WHO Anatomical Therapeutic Chemical (ATC) code. Prescriptions for parenteral nutrition, oxygen, and investigational drugs were not included.

Patient and prescribing-related data were summarized using descriptive statistics (mean \pm standard deviation or median [range] for variables measured on a continuous scale, and frequencies and percentages for categorical variables). The study protocol was approved by the Faculty of Pharmacy Pancasila University Institutional Review Board and Human Ethics Committee at the study hospital.

\section{RESULTS}

There were 67 patients who met the inclusion criteria during the study period, and the characteristics of patients and the diseases are outlined in Table 1. As shown in Table 1, patients ranged in age from 8 months to 17 years, and males constituted more than two-thirds of patients. In addition, there was notable variation in the length of hospitalization and the frequency of hospital admission. The data also uncovered the similar proportion of patients without complications and those with one complication, leaving around $22 \%$ with two complications. Hypertension and chronic kidney disease were the complications seen in these patients.

A total of 1553 drugs consisting of 94 different drugs were prescribed to 67 patients. The drugs included licensed, off-label, and unlicensed drugs. During hospitalization, on average the patients received 20 drugs during the study period. Table 2 details the frequency of drugs in each ATC subcategory. It can be seen in Table 2 that drugs for cardiovascular system $(n=653 ; 42.0 \%)$ accounted for the most frequent drugs prescribed for the patients, followed by various drugs $(n=236 ; 15.2 \%)$ and antineoplastic and immunomodulating agents $(n=227 ; 14.6 \%)$. Of the cardiovascular system drugs, antihypertensive drugs, $(n=598 ; 91.6 \%)$, accounted for nearly all drugs in this class. In regards to "various" drug class, this class included vitamin, minerals, and their combinations. In addition, prednisone ( $n=125 ; 55.0 \%)$ dominated the antineoplastic and immunomodulating drug class; the remaining included methyl prednisolone, mycophenolic acid, and cyclosporine.

Our study uncovered that $1023(65.9 \%)$ of the drugs were used either off-label $(n=789,50.8 \%)$ or unlicensed $(n=234), 15.1 \%$; leaving $34.1 \%$ as on-label drugs. The range of off-label/unlicensed use per patient was

Table 2: Frequency of all drugs, including licensed, off-label, and unlicensed drugs

\begin{tabular}{|c|c|c|c|}
\hline Drug classification $(n=1553)$ & On-label $(n=530)(\%)$ & Off-label $(n=789)(\%)$ & Unlicensed $(n=234)(\%)$ \\
\hline Cardiovascular system $(n=653,42.0 \%)$ & $16(2.5)$ & $538(82.4)$ & $99(15.2)$ \\
\hline $\begin{array}{l}\text { Various (i.e., vitamin, mineral, and } \\
\text { electrolytes) }(n=236,15.2 \%)\end{array}$ & $206(87.3)$ & $11(4.7)$ & $19(8.1)$ \\
\hline $\begin{array}{l}\text { Antineoplastic and immunomodulating } \\
\text { agents }(n=227,14.6 \%)\end{array}$ & $9(3.9)$ & $157(69.2)$ & $61(26.9)$ \\
\hline Nervous system $(n=157,10.1 \%)$ & $55(35.0)$ & $91(57.9)$ & $11(7.0)$ \\
\hline Alimentary tract and metabolism $(n=132,8.5 \%)$ & $58(43.9)$ & $59(44.7)$ & $15(11.4)$ \\
\hline Respiratory system (n=49, 3.2\%) & $35(71.4)$ & $13(26.5)$ & $1(2.0)$ \\
\hline Musculo-skeletal system $(n=10,0.6 \%)$ & $5(50)$ & $4(4)$ & $1(10)$ \\
\hline
\end{tabular}


2-101 drugs. When relating the patients' demographic characteristics specifically age and gender, it appears that pediatric patients with nephrotic syndrome in this study were vulnerable to off-label uses where each patient received at least two off-label drugs. It seems that off-label prescribing in pediatric with nephrotic syndrome was not influenced by age or gender as every patient received off-label drugs. Further, there were 68 different off-label drugs and 35 unlicensed drugs prescribed. When all drugs were classified into their ATC classification categories (Table 2), cardiovascular drugs (82.4\%), antineoplastic and immunomodulating agents (69.2\%), and antiinfectives (59.6\%), respectively, constituted the highest percentages of off-label prescribing. Within specific ATC drug classes, it is shown in Table 2 that the top three percentages of unlicensed drugs were for antineoplastic and immunomodulating agents (26.9\%), antiinfectives (17.9\%), and cardiovascular system (15.2\%), respectively. The highest percentage of on-label drugs was documented from "various" drug classes (87.3\%) specifically vitamins, minerals, and electrolytes. All unlicensed drugs were reformulated due to a lack of availability of a commercial preparation. Further, the 10 most common off-label and unlicensed drugs are shown in Table 3. In line with offlabel drugs, the most commonly prescribed unlicensed drugs were immunosuppressant (i.e., prednisolone) and antihypertensive agents (i.e., lisinopril, valsartan, and furosemide).

A hierarchical approach was used in assigning reasons for prescribing. Order of the hierarchy was age, indication, route of administration and dosage. Fig. 1 describes the reasons for off-label prescribing. As shown in Fig. 1, the high rate of off-label drug use in children was mainly related to age $(n=596,75.5 \%)$ and dosage $(n=187,23.7 \%)$, whereas the least common reason for off-label prescribing was due to indication $(n=6,0.8 \%)$. Further, this study did not find the route of administration as the reason for off-label use.

\section{DISCUSSION}

To the best of our knowledge, this study provides the first data in Indonesia on the prevalence of off-label and unlicensed prescribing in pediatric inpatients with nephrotic syndrome from a major general hospital. Our study uncovered the proportion of off-label and unlicensed prescribing were $50.8 \%$ and $15.1 \%$, respectively. Thus, the overall extent of off-label unlicensed prescribing was $65.9 \%$. It has been evident that the majority of off-label studies have been conducted on patients with varied reasons for admission. Little study has been done to specifically focus on nephrology patients. In comparison to other pediatric nephrology study, the percentage of off-label drugs in this study was considerably higher than that of reported by Yasinta et al. in a children's hospital in China (overall: 16.6\%, nephrotic syndrome: 19.7\%). Yasinta et al. investigated the use of off-label drugs among patients admitted to a specialty ward with a range of nephrology-related diseases [9]. Likewise, when comparing the result with other nonnephrology pediatric studies, the off-label percentage in the present study was much higher than those documented in several overseas studies in the Switzerland (25\%) [13], Malaysia (34\%) [14], Netherlands, Sweden and Italy (39\%) [15]. Nonetheless, similar findings were reported from studies in France (63\%) [16] and Israel (55\%) [17]. In terms of unlicensed prescribing, the result of our study was in line with a number of studies from different countries which reported the proportion of unlicensed drugs in a range of 8\%-16\% [17-20]. The high prevalence of off-label prescribing in the present study was likely due to the nature of specific diagnoses as the focus of investigation instead of including patients with a variety of medical conditions.

Current findings found immunosuppressant (i.e., prednisolone) and antihypertensive agents (i.e., lisinopril, valsartan, and furosemide) being responsible for the most frequent off-label and unlicensed drugs in pediatric inpatiens with nephrotic syndrome. The Kidney Disease: Improving Global Outcome group has released guidelines for management of pediatric nephrotic syndrome, and the guideline has been adopted by pediatric nephrologists worldwide. The guideline
Table 3: The 10 most common off-label and unlicensed drugs

\begin{tabular}{|c|c|c|c|}
\hline \multicolumn{2}{|c|}{ Off-label drugs $(\mathrm{N}=789)$} & \multicolumn{2}{|c|}{ Unlicensed drugs $(\mathrm{N}=234)$} \\
\hline Drugs & Frequency (\%) & Drugs & Frequency (\%) \\
\hline Prednisolone & $125(15.8)$ & Prednisolone & $42(17.9)$ \\
\hline Lisinopril & $121(15.3)$ & Lisinopril & $28(11.9)$ \\
\hline Valsartan & $98(12.4)$ & Valsartan & $23(9.8)$ \\
\hline Furosemide & $78(9.9)$ & Furosemide & $14(6.0)$ \\
\hline $\begin{array}{l}\text { Methyl } \\
\text { prednisolone }\end{array}$ & $74(9.4)$ & Spironolactone & $12(5.1)$ \\
\hline Amlodipine & $72(9.1)$ & $\begin{array}{l}\text { Methyl } \\
\text { prednisolone }\end{array}$ & $10(4.3)$ \\
\hline Carvedilol & $39(4.9)$ & Omeprazole & $10(4.3)$ \\
\hline Losartan & $38(4.8)$ & Cetirizine & $10(4.3)$ \\
\hline Omeprazole & $37(4.7)$ & Co-amoxiclav & $8(3.4)$ \\
\hline Digoxin & $344.3)$ & Amlodipine & $7(3.0)$ \\
\hline
\end{tabular}

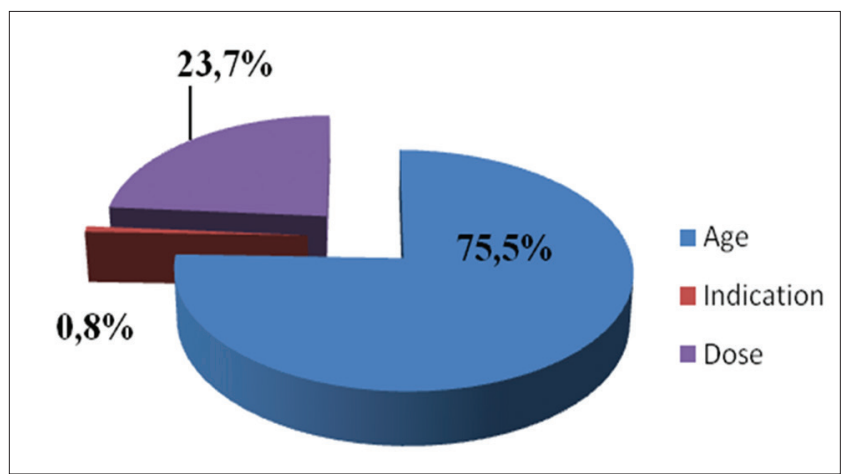

Fig. 1: Reasons for off-label prescribing showing the hierarchical classification used

states that corticosteroids should be the mainstay treatment, in which the guideline recommends induction therapy with oral prednisone or prednisolone for 6 weeks followed with alternate-day maintenance therapy for another 6 weeks. After that, corticosteroid treatment can be ceased or tapered slowly in accordance to patients' response [21]. In addition to steroids, diuretics may benefit patients with symptomatic edema. It has been evident that loop diuretics (e.g., furosemide) may improve troublesome edema which occurs quite frequently. Angiotensin-converting enzyme inhibitors or angiotensin II receptor blockers are often administered for resolving persistent hypertension and proteinuria. Nonetheless, some hypertensive patients may respond well to diuretics [21]. Treatment of nephrotic syndrome may also include management for lipid abnormalities, thromboembolism, and acute kidney failure [22-24].

It is important to note that off-label use of some drugs is clinically appropriate and justified by high-quality evidence [25]. The prescribing guideline in the study hospital has implemented evidenced-based medicine, in which the guideline has been prepared by comprehensively reviewing the recent evidence from both Indonesian and international clinical studies. Thus, off-label use of drugs, in this case, is justified as the clinicians in the study hospital have considered the reliable evidence and their clinical judgment when prescribing the drugs in the off-label manner. From legal perspective, there is no regulation yet in Indonesia as to the use of medicines outside their labels. However, it should be emphasized that clinicians should disclose the reasons for using the medicines in the off-label manner along with the supporting evidence. This information should be written in patients' medical records for documentation and communicated to patients and/or their carers so they can make an informed decision [25]. In regards the reason for unlicensed prescribing, our study corresponded with other pediatric studies in which drug reformulation (so-called extemporaneously prepared drug [EPD]) was the main reason for unlicensed use. EPD 
occurs due to the fact that the availability of a specific drug or dosage or formulation suitable for pediatric patients was very limited [26]. It is unfortunate that EPD use in practice was not supported by reliable and adequate information signifying the issue of quality assurance [27].

The reasons for off-label and unlicensed prescribing are mainly attributed to lack of quality clinical trials in children and subsequently inadequate pediatric labeling of drugs. In addition, the complex procedures in revising the approved drug information may exacerbate the situation leading to the extensive use of off-label drugs [27]. Nonetheless, it is noteworthy to realize that the scientific literature is often available and adequately supports the off-label use of certain medicines [28]. Thus, it can be understood that some countries such as the Unites States and European countries under the European Union have introduced the new legislation to facilitate the availability of evidence-based drug therapy for children. The legislation has encompassed many aspects including economic incentives for pharmaceutical industry to undertake clinical trials involving pediatric population, and pressure for national regulatory agencies and research organizations to ensure the performance of high ethical and scientific quality of pediatric clinical trials $[29,30]$. The legislation also focuses on the measure to resolve the complexity in updating the product information. Previously, the pharmaceutical industries should organize the clinical trials and submit the required documents to the regulatory agency if they want to revise the product information (i.e., adding the new indication). The revision process is complex and takes before authority approval. However, the updating process based on recent legislation can be done by reviewing the pediatric studies justifying the off-label use of the reviewed medicines. If the studies are justified, the regulatory agency may then update the product information $[29,30]$. Indonesia may undertake the similar attempts to resolve some issues related to off-label medicines in children, in particular, supporting pediatric clinical trials and updating the product information in IONI as the national drug information source.

A number of limitations need to be acknowledged in the present study. First, the hierarchical approach in classifying the off-label drugs suffered an issue where in some cases the proportion of drugs classified as off-label due to indication, route of administration or dose would have been higher if the approach had not been used. Further, the classification system may lower the proportion of unlicensed drugs reported in this study. Second, this study was conducted in one hospital, which diminishes the ability to generalize the findings. It is recommended future studies involve multiple institutions and possibly pediatric hospitals allowing the comparison between pediatric wards in general hospital and children's hospital. In addition, this study uncovered difficulties to draw accurate comparison with other studies due to variations in settings, design, size, method, and operational definitions of off-label and unlicensed medications. Nevertheless, the findings of the present study may provide the overall view of off-label and unlicensed prescribing in the pediatric population.

\section{CONCLUSION}

Despite the high prevalence of off-label use in pediatric patients with nephrotic syndrome, this use is supported by evidence-based prescribing. Further, there remains a need for supporting clinical trials for pediatric drugs and subsequently updating IONI as the standard of drug information in Indonesia to provide complete product information for pediatric use.

\section{ACKNOWLEDGMENT}

We would like to acknowledge Faculty of Pharmacy Pancasila University, for granting research funding to support this study.

\section{REFERENCES}

1. The American Academy of Pediatrics. Policy statement: Off-label use of drugs in children. Pediatrics 2014;133:563-7.
2. Turner S, Longworth A, Nunn AJ, Choonara I. Unlicensed and off label drug use in paediatric wards: Prospective study. BMJ 1998;316(7128):343-5.

3. 't Jong GW, van der Linden PD, Bakker EM, van der Lely N, Eland IA, Stricker BH, et al. Unlicensed and off-label drug use in a paediatric ward of a general hospital in the Netherlands. Eur J Clin Pharmacol 2002;58(4):293-7.

4. Sinha Y, Cranswick NE. How to use medicines in children: Principles of paediatric clinical pharmacology. J Paediatr Child Health 2007;43(3):107-11

5. Shirkey H. Therapeutic orphans. J Pediatr 1968;72(1):119-20.

6. Czarniak P, Bint L, Favié L, Parsons R, Hughes J, Sunderland B. Clinical setting influences off-label and unlicensed prescribing in a paediatric teaching hospital. PLoS One 2015;10(3):e0120630.

7. O'Donnell CP, Stone RJ, Morley CJ. Unlicensed and off-label drug use in an Australian neonatal intensive care unit. Pediatrics 2002;110(5):e52.

8. Lindell-Osuagwu L, Korhonen MJ, Saano S, Helin-Tanninen M, Naaranlahti T, Kokki H. Off-label and unlicensed drug prescribing in three paediatric wards in Finland and review of the international literature. J Clin Pharm Ther 2009;34(3):277-87.

9. Yasinta M, Che RC, Hu CY, Du XH, Ding GX, Huang SM. Use of off-label nephrology-related drugs in hospitalized pediatric patients: A retrospective study. World J Pediatr 2016;12(2):236-42.

10. European Medicines Agency. ICH Topic E11 Clinical Investigation of Medicinal Products in the Paediatric Population; 2001. Available from: http://www.ema.europa.edu/docs/en_GB/document_library/Scientific guideline/2009/09/WC500002926.pd̄f.

11. Badan Pengawasan Obat dan Makanan. Informatorium Obat Nasional Indonesia. Jakarta: Badan Pengawasan Obat dan Makanan; 2015. Available from: http://www.pionas.pom.go.id/ioni.

12. Hsien L, Breddemann A, Frobel AK, Heusch A, Schmidt KG, Läer S. Off-label drug use among hospitalised children: Identifying areas with the highest need for research. Pharm World Sci 2008;30(5):497-502.

13. Di Paolo ER, Stoetter H, Cotting J, Frey P, Gehri M, Beck-Popovic M, et al. Unlicensed and off-label drug use in a Swiss paediatric university hospital. Swiss Med Wkly 2006;136(13-14):218-22.

14. Lee JL, Redzuan AM, Shah NM. Unlicensed and off-label use of medicines in children admitted to the intensive care units of a hospital in Malaysia. Int J Clin Pharm 2013;35(6):1025-9.

15. Conroy S, Choonara I, Impicciatore P, Mohn A, Arnell H, Rane A, et al. Survey of unlicensed and off label drug use in paediatric wards in European countries. European Network for Drug Investigation in Children. BMJ 2000 8;320(7227):79-82.

16. Avenel S, Bomkratz A, Dassieu G, Janaud JC, Danan C. The incidence of prescriptions without marketing product license in a neonatal intensive care unit. Arch Pediatr 2000;7(2):143-7.

17. Barr J, Brenner-Zada G, Heiman E, Pareth G, Bulkowstein M, Greenberg R, et al. Unlicensed and off-label medication use in a neonatal intensive care unit: A prospective study. Am J Perinatol 2002;19(2):67-72.

18. Conroy S, McIntyre J, Choonara I. Unlicensed and off label drug use in neonates. Arch Dis Child Fetal Neonatal Ed 1999;80(2):F142-4.

19. Palcevski G, Skocibušic N, Vlahovic-Palcevski V. Unlicensed and offlabel drug use in hospitalized children in Croatia: A cross-sectional survey. Eur J Clin Pharmacol 2012;68(7):1073-7.

20. Gavrilov V, Lifshitz M, Levy J, Gorodischer R. Unlicensed and offlabel medication use in a general pediatrics ambulatory hospital unit in Israel. Isr Med Assoc J 2000;2(8):595-7.

21. Lombel RM, Gipson DS, Hodson EM; Kidney Disease: Improving Global Outcomes. Treatment of steroid-sensitive nephrotic syndrome: New guidelines from KDIGO. Pediatr Nephrol 2013;28(3):415-26.

22. Rheault MN, Zhang L, Selewski DT, Kallash M, Tran CL, Seamon M, et al. AKI in Children Hospitalized with Nephrotic Syndrome. Clin J Am Soc Nephrol 2015;10(1):2110-8.

23. Prescott WA Jr, Streetman DA, Streetman DS. The potential role of HMG-CoA reductase inhibitors in pediatric nephrotic syndrome. Ann Pharmacother 2004;38(12):2105-14

24. Zaffanello M, Franchini M. Thromboembolism in childhood nephrotic syndrome: A rare but serious complication. Hematology 2007(1);12:69-73.

25. Hattingh L. Guidelines for off-label medicine use. Aust Pharm 2014;30:70-1.

26. Brion F, Nunn AJ, Rieutord A. Extemporaneous (magistral) preparation of oral medicines for children in European hospitals. Acta Paediatr 2003;92(4):486-90.

27. Kimland E, Odlind V. Off-label drug use in pediatric patients. Clin Pharmacol Ther 2012;91(5):796-801. 
28. Lass J, Irs A, Pisarev H, Leinemann T, Lutsar I. Off label use of prescription medicines in children in outpatient setting in Estonia is common. Pharmacoepidemiol Drug Saf 2011;20:474-81.

29. European Medicines Agency. Medicines for children; 2006. Available from: http://www.ema.europa.eu/ema/index.jsp?curl=pages/ regulation/document listing/document listing 000068 . jsp\&mid=WC0b01ac058002 5b8b

30. The United States Congress. Pediatric Research Equity Act 2003; (S.650). Available from: http://www.govtrack.us/congress/ bills/108/s650 